\title{
Applying artificial neural networks for modelling ship speed and fuel consumption
}

\author{
Wieslaw Tarelko ${ }^{1}$ (D) Krzysztof Rudzki ${ }^{2}$ (D)
}

Received: 5 August 2019/Accepted: 5 June 2020/Published online: 16 June 2020

(C) The Author(s) 2020

\begin{abstract}
This paper deals with modelling ship speed and fuel consumption using artificial neural network (ANN) techniques. These tools allowed us to develop ANN models that can be used for predicting both the fuel consumption and the travel time to the destination for commanded outputs (the ship driveline shaft speed and the propeller pitch) selected by the ship operator. In these cases, due to variable environmental conditions, making decisions regarding setting the proper commanded outputs to is extraordinarily difficult. To support such decisions, we have developed a decision support system. Its main elements are the ANN models enabling ship fuel consumption and speed prediction. To collect data needed for building ANN models, sea trials were conducted. In this paper, the decision support system concept, input and variables of the ship driveline system models, and data acquisition methods are presented. Based on them, we developed appropriate ANN models. Subsequently, we performed a quality assessment of the collected data set, data normalization and division of the data set, selection of an ANN model architecture and assessment of their quality.
\end{abstract}

Keywords Artificial neural network $\cdot$ Modelling $\cdot$ Ship speed $\cdot$ Engine fuel consumption

\section{Introduction}

Ship owners and operators of different types of ships are interested in decreasing the costs related to the effectiveness of their operation. These costs are mainly associated with fuel consumption and operational losses, e.g. excessive travel time to the destination. In the case of ships equipped with a combustion engine (CE) coupled to a controllable pitch propeller (CPP), effectively managing both the fuel consumption and travel time to the destination is related to the optimal choice of commanded outputs determining the work of such a driveline system. This system generates thrust to move a ship across the water at the desired speed with different levels of fuel consumption for various combinations of the commanded outputs,

Wieslaw Tarelko

wieslaw.tarelko@pg.edu.pl

1 Faculty of Ocean Engineering and Ship Technology, Gdansk University of Technology, Narutowicza 11, 80-333 Gdańsk, Poland

2 Faculty of Marine Engineering, Gdynia Maritime University, Morska 81-87, 81-225 Gdynia, Poland namely the driveline shaft speed and the CPP pitch. The optimal combination of speed and pitch depends on several operational conditions and, therefore, must be subjected to dynamic optimization. For this purpose, the most operated ships used speed/pitch ratio controllers. In such a ship driveline system, the commanded torque is controlled to maintain a certain shaft speed.

However, there are ships which are not equipped with this kind of controller and the shaft speed or the CPP pitch ratio is used to control the propeller thrust indirectly. In such cases, due to variable environmental conditions (mainly weather conditions at sea), making decisions about setting the commanded outputs to ensure rational fuel use and the desired ship speed is extraordinarily difficult.

A literature review carried out in [1] showed that there are some methods that could support selection of the commanded outputs for a ship's propulsion system equipped with the CPP. They are mainly based on models developed by use of polynomial or regression equations. As a rule, algorithms for solving of such equations in both types of models are too complex. For this reason, many assumptions are used that simplify these models and significantly decrease usefulness of these methods. Moreover, 
their disadvantages are the difficulties with estimating sea conditions. Nonetheless, knowledge of these conditions is essential to selecting the appropriate propeller pitches and engine rotational speeds.

For this reason, it would be useful to develop computerbased tools to support such decisions. The base of such tools should be mathematical models connecting fuel consumption and travel time to the destination with the commanded outputs and operational conditions subjected to the propulsion thrust. An analysis of bibliographic references concerning methods of setting the commanded outputs of this kind of ship drivelines was presented by Rudzki [1], who showed that the existing methods do not include models that allow formalizing the required heuristic knowledge. In our opinion, artificial neural network (ANN) techniques can be used for obtaining such models and can be used for better predicting both the fuel consumption and travel time to the destination for the selected commanded outputs and the observed parameters of operational conditions owing to their high accuracy, adequacy and quite promising applications in practice.

In this case, an important advantage of the ANN method is that it does not require mathematical relations of the input data and output data. Moreover, this technique allows to solve our problem that is not very well formulated formally.

This paper deals with the selected issues of developing ANN models combining the mentioned parameters. In our approach, to collect data needed for building ANN models, sea trials were conducted.

\section{Literature review}

Two ANN models are needed to develop a computer-aided system supporting decision-making regarding setting the ship driveline commanded outputs to ensure rational fuel use and the desired ship speed. The first ANN model should connect a fuel consumption process to factors that influence this process, and the second ANN model connects ship speed to factors that influence this speed.

In a mathematical description of these kinds of phenomena, two fundamental approaches are used:

- White box modelling,

- Black box modelling.

In practice, most developed models are obtained using gray box modelling that combines a partial theoretical structure with data to complete the models.

White box models, also called cause-effect models, deal with the variables impacting the distribution of a phenomenon and describe a physical process. They integrate existing knowledge about processes into a set of relationships (equations) for quantifying those processes. The most commonly used method to develop white box models of dynamic systems is the balance method. In systems where we must deal with physical quantities, balancing is carried out for parameters that are subordinate to the laws of conservation of energy and momentum.

Nevertheless, applying the balance method to modelling both fuel combustion and the ship motion processes to obtain a decision-making model supporting decision-making regarding the commanded outputs of the ship driveline system is practically impossible. This is because the equations describing these processes are so complex that for the given conditions of explicitness, they are not solvable. Moreover, processes running in the considered systems are dependent on many parameters at the same time and they influence the observed phenomenon in varying degrees (for example, meteorological conditions).

With some simplifying assumptions, we could try to bring these equations to more simple forms such as linear, parabolic or hyperbolic equations. Unfortunately, the equations describing the considered processes cannot be subjected to linearization procedures or they are simple enough for presentation in an unsophisticated mathematical form. In addition, analytical solutions of these equations are possible only by using such approximations, so that the results lose their practical utility.

Therefore, we should look for alternative modelling methods. For example, we could build the necessary models using the black box modelling method.

In general, black box models help us in understanding underlying processes. We can receive their descriptions without necessarily analysing or providing their causes. A procedure for setting up this kind of model is as follows:

- Carrying out measurements,

- Analysing the obtained results and seeking essential parameters for the considered issue.

- Checking which initial conditions can be neglected or not,

- Finding a functional dependency or simply guessing it based on our intuition,

- Fitting parameters to the selected function,

- Comparing the received model with the results of measurements.

If the conformity is not acceptable, we should take one or several steps back (we can also conduct additional measurements).

The starting point for using this procedure is to collect appropriate data by carrying out measurements or using historical records. As a rule, we should divide the collected data into those that will be estimated, which is dependent variables, and those that will be used as necessary conditions, which is independent variables. 
There are a lot of scientific research papers that applied similar procedures in various areas of science. Most of them are based on new achievements in ANN, for example [2-6], whereas some of them were applied in maritime industry, for example [7-9].

In the classical approach for modelling similar phenomena, statistical models are most commonly used. In the field of ocean engineering, interpolating and predicting hull resistance from model experiments and tank testing have traditionally been done using statistical regression equations. For example, such models are used to determine parameters characterizing ship propulsion efficiency in the early stages of its design [10, 11]. Analysing application regression relationships for modelling the selection of optimal drive propulsion parameters was presented by Rudzki and Tarelko [12].

To receive models that could be used in the considered decision-making system, a black box model in the form of multiple regressions was developed [1]. The same data needed for building ANN models were used to build the regression models. These data directly connect both the fuel consumption and the travel time to the destination with the commanded outputs and parameters of operational conditions subjected to the propulsion thrust.

However, the obtained results show some limitations.

- There is no certainty that the analysed set of independent variables is sufficient,

- The regression function type is not known; therefore, it is a problem of selecting the regression function shapes and a set of independent variables,

- All attempts to select the most appropriate form of polynomial regression models for both dependent variables showed that such trials slightly increased model adequateness.

In contrast, ANN models enhance the generalizability and extrapolation capability and do not require a priori assumptions of function forms. Therefore, they can be used to develop a computer-aided system supporting decisionmaking regarding setting the ship driveline commanded outputs to ensure rational fuel use and the desired ship speed.

Applying ANN models for predicting ship fuel consumption or ship speed for various operational conditions is not presented in many publications.

Historical data acquired from ship logs (records of important events in the management, operation, and navigation of a ship) were used in all considered ANN models to predict ship fuel consumption.

In Arslan, Bal Beşikçi and Ölçer [13] and Bal Beşikçi, Arslan, Turan and Ölçer [14], decision support systems employing ANN based on fuel prediction models were developed. These models used operating data called "noon data' obtained from ship noon reports. ${ }^{1}$ The input parameters were seven variables, a ship's speed, the rotational speed of the main engine, mean draft, trim, cargo quantity on board, wind and sea effects, and the output variable of the ANN model was ship fuel consumption. In both studies, neural network models were implemented using the Neural Network Toolbox in MATLAB 2010a. To design and construct the ANN, the data set derived from 233 [14] and 3646 (7 tanker ships) [13] noon reports was used. Initially, $70 \%$ of the noon reports were randomly selected for training, and the remaining $30 \%$ was used for validation. The modelling method for ANN was based on the backpropagation learning algorithm used in feedforward with one hidden layer. The learning algorithm used in these studies was Levenberg-Marquardt, the activation function was hyperbolic tangent sigmoid transfer functions, and the number of epochs was set to 10,000 . Additionally, the performance of the developed ANN model was compared with the multiple regression model [13]. For both training and validation data, the correlation between the actual and predicted fuel consumption for the ANN model was shown to be much higher than for the linear regression model.

Pedersen and Larsen [15] presented a method using ANN to predict propulsive power from theoretical variables influencing ship resistance, such as a ship speed, relative wind speed and direction, air temperature and seawater temperature. Three data input sources were used to train and predict the propulsive power, onboard measured, noon report data and weather and sea state information based on the hindcast approach. ${ }^{2}$ To design the ANN, a data set was derived from 323 samples of the noon reports. It was only trained for 5 and 20 hidden layers as these are the extremes as justified by Pedersen and Larsen. The ANN used noon report data to predict the specific fuel consumption with an accuracy of about $7 \%$. It was noted that this accuracy was obtained using 'time' as an input variable; this indicates that it is possible to detect a trend in fuel consumption over time.

Du and Meng [16, 17] proposed a model that complies with the fundamentals of ship propulsion and can precisely quantify the synergetic influence of several determinants on ship fuel efficiency. It also develops a ship fuel consumption management scheme based on tangible ANN models. They adopted a two-step procedure for ship fuel consumption assessment, estimating the ship engine rotational speed and then estimating engine power based on the

\footnotetext{
${ }^{1}$ Noon reports-daily data sheets prepared by the ship chief engineer. They provide the vessel position and other data necessary to evaluate the ship performance based on its speed and environmental forces including information on daily fuel consumption.

2 A hindcast approach-atmospheric and ocean response models for a historical period to develop the specification of climate and extremes used in some applications.
} 
obtained speed. The fuel consumption was calculated as a product of the estimated parameters. The ANN model input variables were speed, displacement, wind force, wind wave height, swell height, sea current factor and trim. The data set necessary to design and construct the ANN model was acquired from noon reports of 3 ships, 121, 160 and 153 reports, respectively. In conclusion, they stated that an ANN model with a simple model structure (1 hidden layer) exhibits the best (surely practically acceptable) fit performance.

Applying ANN models to predict ship speed for various operational conditions was not presented directly in the subject publications. In practice, the power required to move the ship hull at a given speed in the absence of propeller action can be determined from towing tank experiments at various speeds of a model ship. Therefore, we analysed ANN models that combine the ship resistance or power with parameters that influence these ship characteristics.

The applicability of ANN to the ship resistance prediction as an alternative to more traditional statistical regression models was investigated by Couser, Mason, Mason, Smith and von Konsky [18]. The ANN network was used as an interpolation tool to predict the residual resistance for a series of catamaran-type vessels. ANN was able to produce results of sufficient accuracy to be useful for the preliminary prediction of vessel resistance. To design and construct the ANN model, Couser et al. used a single hidden layer and 15 neurons in the hidden layer. In their opinion:

- The addition of further hidden layers did not appear to improve the accuracy of the ANN and only added to its complexity and required training time,

- The use of dedicated software makes it very quick and easy to produce and train an ANN capable of modelling hull resistance problems compared to traditional statistical methods.

A similar approach to predict ship's resistance using ANN is presented by Grabowska and Szczuko [19]. Their research used the parameters of 7 already built off shore vessels, with model parameters available as a result of tests conducted on a towing tank (a physical basin used to carry out hydrodynamic tests with ship models). The input and output layers were determined based on the input data dimensionality and required output; thus, the number of hidden layer neurons was estimated as a geometric mean using the formula proposed by Bishop [20]. The automatic network architecture exploration revealed that 24 neurons give the best accuracy. Therefore, several hidden layer configurations were tested to investigate the possible impact of architecture on the results. Grabowska and Szczuko evaluated seven training algorithms. They chose the Quick Propagation algorithm for further study because it gave the most promising results for correlation between target and output values, correlation coefficient $\left(R^{2}\right)$ and absolute validation error. To find the best network architecture, several cases were considered with 4, 6, 9, 12, 15, 18 and 24 neurons in a hidden layer; 24 neurons give the lowest absolute validation error; therefore, the network architecture 20-24-1 was used in the follow-up study. In conclusion, they stated that the proposed and trained network showed satisfactory accuracy compared with the results from the model tests. Nevertheless, the architecture might be improved, and further study on this approach should be undertaken.

In Mason, Couser, Mason, Smith and von Konsky [21], ANN was fitted directly to the original towing tank test data and different ANN architectures were investigated. The data used for the investigation originated from a series of tank tests using Holtrop and Mennen's method [11]. The initial test network architectures were constrained to three layers, one each for input, hidden and output layers. Training runs used a quasi-Newton method for 50,000 iterations, and 10 retrains were performed for each network topology to minimize error. The range of architectures searched was from 4 inputs, 4 hidden layer neurons and 1 output to 4 inputs, 17 hidden layer neurons and 1 output. In Mason et al.'s opinion, the study demonstrated that

- A sparse data set with a relatively high degree of additional meaningless information can be fitted effectively using a feedforward ANN,

- There may be benefits resulting from networks with two hidden layers rather than one.

Ortigosa, López and García [22, 23] presented an ANN approach to predicting two resistance components. To provide estimates of the form coefficient and the wave's coefficient as functions of ship hull geometry coefficients and the Froude number, the multilayer perceptron (MLP) was trained with generated data and experimental data. An empirical model was constructed using a neural network. The data necessary to train ANN were generated using Holtrop and Mennen's method [11] that provides a prediction of the total resistance's components. The MLP with a sigmoid hidden layer and two linear output layers was used. The selected training algorithm was the quasi-Newton method with Broyden-Fletcher-Goldfarb-Shanno train direction and Brent optimal train rate described by Bishop [20]. Different numbers of neurons in the hidden layer were tested, and the network architecture providing the best generalization properties for the validation data set was adopted. The optimal ANN architecture was 5 inputs, 9 hidden layer neurons and 2 outputs. The ANN results were compared against those provided by Holtrop and Mennen's method for estimating the form factor and the wave's 
coefficients, and it was found that the quality of the prediction with the ANN is improved over the entire range of data.

This analysis of references concerning the ANN approach to modelling ship fuel consumption and hull resistance shows us that.

- Historical data derived from ship logs (noon reports) have been used to model fuel consumption as the input variables,

- Design data (parameters of ship hull geometry) or experimental data (tank tests) have been used to model ship resistance as the input variables,

- There is a lack of detailed information regarding:

- Methods for carrying out measurements,

- Types of propellers applied in ship driveline systems.

Moreover, the major reference for designing and constructing ANNs was Bishop's book [20].

In our approach, to design and construct more adequate ANN models enabling ship fuel consumption and speed prediction, we decided to plan a dedicated experiment. Such an experiment was conducted with different commanded outputs of the ship driveline system for various environmental conditions at sea.

\section{Decision support system and its components}

\subsection{Decision support system concept}

As previously mentioned, there are no methods enabling one to select commanded outputs based on formalized heuristic knowledge in cases of ships equipped with CE coupled to CPP without speed/pitch ratio controllers. Therefore, operators (a master or officers in charge) of such ships set the shaft speed and/or the CPP pitch ratio to control the propeller thrust indirectly. As a rule, they select values of the commanded outputs based on own experience, intuition and all available information regarding operational conditions. In our approach, the term 'operational conditions' refers to the physical environment where the ship operates, i.e. the wind, wave and current conditions encountered by the ship.

Sometimes these settings can be irrational or inappropriate. To avoid such situations, a decision support system (DSS) should be developed.

The developed DSS consists of the following main components (Fig. 1).

- A data acquisition module with many inputs in the form of uncontrollable input variables and one output in the form of a vector of normalized ANN data,

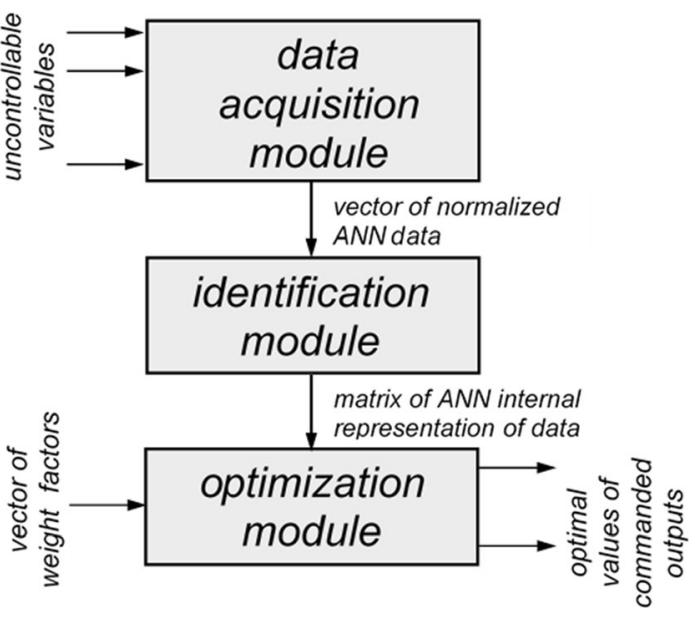

Fig. 1 DSS block diagram

- An identification module with the normalized ANN output values resulting from the previous module as the input and one output in the form of a matrix representing the ANN internal representation of data enabling the prediction of ship fuel consumption and speed,

- An optimization module with two inputs: the matrix representing ANN internal representation of data resulting from the former module and the vector of weight factors of the two-objective optimization model, and two outputs with the optimal commanded outputs.

To develop the DSS, it was necessary to:

- Define input and variables of the ship driveline system models,

- Build models enabling ship fuel consumption and speed prediction using ANN techniques,

- Build a decision-making model using multi-objective optimization methods.

To build these models, we considered a ship as a solid object located on the border of water and air, partly immersed in each and typically remaining in relative motion, which allows us to define variables for black box and decision-making models. Initially, we presented this

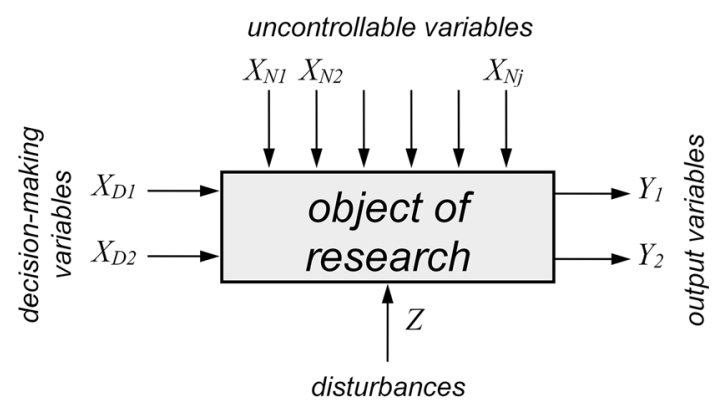

Fig. 2 'Black box' model 
problem in the form of a 'black box' subjected to a variety of factors (Fig. 2).

As decision-making input variables, $X_{D i}$, factors ensuring the desired ship motion (the propeller thrust), we selected the commanded outputs of the ship driveline system, that is, both the CE rotational speed and the CPP pitch. A variety of factors that affect the ship motion and result from operational conditions was nominated as the uncontrollable input variables, $X_{N j}$. As the model output variables, $Y_{k}$, factors associated with fuel consumption and operational losses, we selected the CE fuel consumption and the ship speed. Other factors affecting the ship motion but which are difficult and sometimes even impossible to observe, and for which there is no possibility to impact their values, were set as the model disturbances, $Z$. The input and output variables are presented in Table 1.

Taking into account the distinguished variables of the black box model, the problem of decision-making can be formulated as follows:

what should the values of the decision-making variables, $X_{D i}$, be for the given values of the uncontrollable variables, $X_{N j}$, to provide the desired values of the output variables, $Y_{k}$.

The model output variables, $Y_{k}$, constitute criteria for the two-objective optimization problem. The first objective is that the fuel consumption should be as small as possible, and the second is that the ship speed should be as high as possible. The weighted sum method that minimizes a positively weighted convex sum of these objectives was adopted as the substitute objective function:

$Z=w_{q 1} \cdot Y_{1}-\left(1-w_{q 1}\right) \cdot Y_{2} \rightarrow \mathrm{MIN}$

and $w_{q 1}+w_{q 2}=1$

where $Z$ - the substitute objective function of a two-objective optimization problem, $Y_{1}$-the normalized hourly fuel consumption rate, $Y_{2}$ - the normalized instantaneous speed over the ground, $w_{q 1}$ - the weight factor of criterion $1, w_{q 2}$ - the weight factor of criterion 2 . The substitute objective function, $Z$, was modified by introducing a new output variable representing the loss of speed of a vessel because the graph curves obtained from both ANN models have consistent slopes. It was a purely technical approach that does not alter the optimization results. Finally, the substitute objective function obtained the following form:

$Z=w_{q 1} \cdot\left(Y_{1}-1\right)+\left(w_{q 1}-1\right) \cdot Y_{2} \rightarrow \mathrm{MIN}$

Based on the nominated optimization criteria, their mathematical descriptions and the determined constraints, an algorithm was designed for the two-objective optimization. All necessary calculations were performed using code developed from the MATLAB optimization toolbox. More detailed information can be found in Rudzki [1].

\subsection{Data acquisition}

To collect the data necessary to create the ANN models, an experiment was conducted on the tall ship Pogoria. This ship is a barquentine, which means that the main source of her propulsion is sails. Nevertheless, Pogoria is equipped with a $255-\mathrm{kW}$ drive engine, which drives a CPP with a $356 \mathrm{rpm}$ nominal speed through a 1:4.5 reduction gear ratio. The selection of the $\mathrm{CE}$ rotational speed and the $\mathrm{CPP}$ pitch is performed by two command levers located on the navigating bridge. Therefore, we decided to conduct the dedicated experiment at sea with different commanded outputs of the ship driveline system and different ship

Table 1 Output and input variables of ANN models

\begin{tabular}{|c|c|c|c|c|c|c|}
\hline \multirow[t]{2}{*}{ Variable name } & \multirow[t]{2}{*}{ Variable identifier } & \multicolumn{2}{|c|}{$\begin{array}{l}\text { Possible } \\
\text { limit values }\end{array}$} & \multicolumn{2}{|c|}{$\begin{array}{l}\text { Observed } \\
\text { values }\end{array}$} & \multirow[t]{2}{*}{ Unit } \\
\hline & & Min & $\operatorname{Max}$ & Min & Max & \\
\hline CE rotational speed & $X_{1}$ & 800 & 2000 & 1100 & 1950 & {$[\mathrm{rpm}]$} \\
\hline CPP pitch & $X_{2}$ & 0 & 19 & 0 & 18 & [Pitch scale $]$ \\
\hline Wind direction angle in relation to the longitudinal axis of the ship & $X_{3}$ & -90 & 90 & -90 & 90 & {$\left[{ }^{\circ}\right]$} \\
\hline Wind speed & $X_{4}$ & 0 & - & 0 & 48 & {$[\mathrm{knot}]$} \\
\hline State of the sea & $X_{5}$ & 0 & 10 & 0 & 8 & [Degree $]$ \\
\hline Tidal current direction angle in relation to the longitudinal axis of the ship & $X_{6}$ & -90 & 90 & -83 & 90 & {$\left[{ }^{\circ}\right]$} \\
\hline Tidal current speed & $X_{7}$ & 0 & - & 0 & 3.1 & [Knot] \\
\hline Time since the last docking of the ship & $X_{8}$ & 0 & - & 0 & 24 & [Months] \\
\hline Hourly fuel consumption rate & $Y_{1}$ & - & $\approx 65$ & 6 & 48.9 & {$\left[\mathrm{dm}^{3} / \mathrm{h}\right]$} \\
\hline Instantaneous speed over the ground & $Y_{2}$ & 0 & - & 0 & 11.2 & {$[$ Knot $]$} \\
\hline
\end{tabular}


courses for various environmental conditions at sea. These experiments were carried out with the engine as the main source of power (without using sails).

To obtain appropriate measurements, we used different onboard instruments and a specially developed measuring device. More information regarding measurement methods is presented in Rudzki and Tarelko [12]. Values for the selected input and output variables of the ANN models were obtained from 315 observations carried out during sea trials. Their possible and observed ranges are presented in Table 1, and the collected results are published in Rudzki [1].

\section{Development of ANN models}

Artificial neural network techniques were used to build models enabling ship fuel consumption and speed prediction, which are necessary to develop DSS. The input and output variables presented in Table 1 and their values acquired from the dedicated experiment conducted at open sea were used to design and construct these models. Generally, the design and construction of ANN models consist of the following main actions.

- Data normalization,

- Division of the data set,

- Architecture of ANN models,

- Assessment of ANN model quality.

\subsection{Quality assessment of the collected data set}

Initially, a quality assessment of the collected data set was conducted before implementing these actions. This was done using the STATISTICA software module. To analyse the correctness of the factor spatial structure, the central agglomeration procedure and six hierarchical cluster algorithms were used. These statistical methods allowed us to find relatively homogeneous clusters of cases based on dissimilarities or distances between the observed objects. As a result, we received many cluster hierarchies that are commonly displayed as tree diagrams called dendrograms. An example of the dendrogram for the input variables (without the variable: 'time since the last docking of the ship') and the output variable 'hourly fuel consumption rate' using a method called the City block (Manhattan) distance is shown in Fig. 3.

The vertical axis of the dendrogram represents the distance between clusters, and the horizontal distance represents the objects and clusters. All dendrograms obtained using these methods have similar structures. The objects are practically separated by every method and every metric, and similarly-with the exception of specific numeral

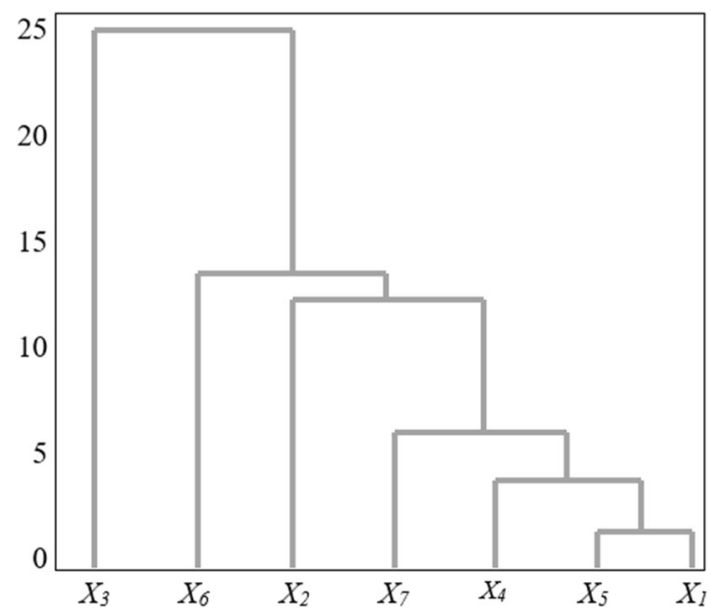

Fig. 3 Dendrogram of the hierarchical cluster analysis (metric distance: City Block (Manhattan)

values of similarity. Based on the correct clustering, we agreed that the selected variables are appropriate for the collected data set.

\subsection{Data normalization and division of the data set}

In the next steps, the MATLAB Neural Network Toolbox was applied to develop the desired ANN models.

In the first step of developing ANN models, linear normalization with $10 \%$ reserve was used. For data with positive values of the variables, that is, $X_{1}, X_{2}, X_{4}, X_{5}, X_{7}$, $X_{8}, Y_{1}$ and $Y_{2}$, the range was [0.1, 0.9], whereas for data with negative values of the variables, that is, $X_{3}$ and $X_{6}$, the range was $[-0.9,0.9]$. The straight-line coefficients were calculated using the following formulas:

- For data with positive values of the variables.

$a_{i}=\frac{0.8}{x_{i \max }-x_{i \min }}$ and $b_{i}=0.9-\frac{0.8 \cdot x_{i \max }}{x_{i \max }-x_{i \min }}$.

- For data with negative values of the variables.

$a_{j}=\frac{1.8}{x_{j \max }-x_{j \min }}$ and $b_{j}=0.9-\frac{1.8 \cdot x_{j \max }}{x_{j \max }-x_{j \min }}$.

This allowed us to extrapolate beyond the observed ranges, e.g. greater than the observed values of the wind force or sea state.

Next, a cross-validation procedure was performed to ensure the accuracy of the results. The idea of this procedure is to split the training set into two, a set of examples to train with and a validation set. To improve both the efficiency and the quality of ANN training, the data were randomly divided into three sets (training, testing and 
validation). We examined four methods offered by the MATLAB Neural Network Toolbox that enables splitting the data set. As a result, we selected the dividerand function to create random indices for these sets. Subsequently, we obtained three subsets in the following ratio:

- Training set $-70 \%$ of the data,

- Validation set-20\% of the data,

- Testing set-10\% of the data.

\subsection{Architecture of ANN models}

The most important stage in building ANN models is to design and construct the appropriate network architecture. It determines the model significance and adequacy. To design the suitable network architecture, it is necessary to decide several important parameters, such as the linearity or non-linearity of the considered problem, the number of network outputs, hidden layers, neurons in the hidden layers, epochs of network learning, the type of the activation function, quality of fit to the data, algorithm and step learning.

Results of the preliminary sea trials show that the considered issue is inherently a nonlinear phenomenon [12]. Therefore, a nonlinear neural network was selected to design and construct its architecture.

To develop DSS, we need to build two ANN models with two separate outputs, which could be realized by one common or two separate networks. In the second case, there is a contradiction between the model outputs. Therefore, we decided to build two separate networks with a single output for each model according to the suggestions presented in Tadeusiewicz [24]. This approach enabled the optimal adjustment of the network settings.

The next stages in designing a network architecture are to choose the number of hidden layers and epochs of network learning. In the developed network, information moves in only one direction without any cycles or loops. In ANN techniques, these structures are called feedforward networks and they are described by MLP networks in a relatively comfortable way. Therefore, the function feedforward was chosen from the MATLAB Neural Network Toolbox. It allowed us to specify successive parameters and learning processes of the network structures like the number of hidden layers, the number of neurons in the hidden layers and the activation functions.

All actions needed to develop the ANN models were performed based on the MATLAB Neural Network Toolbox and its functions. In particular, the number of epochs, the type of activation function for the neurons, the ANN fit quality and the ANN training step were completed, and the appropriate MATLAB scripts were developed. Extensive computational experiments generated two separate ANNs

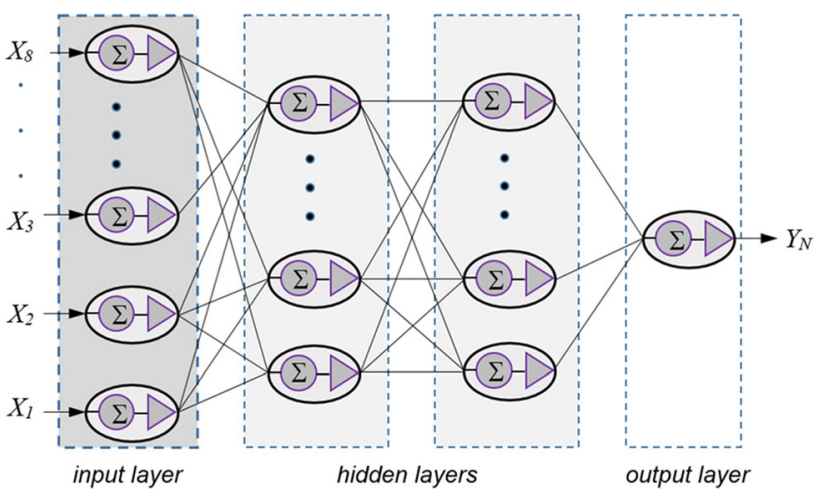

Fig. 4 Principal architecture of the developed ANNs

for both output variables $Y_{1}$ 'hourly fuel consumption rate' and $Y_{2}$ 'instantaneous speed over the ground'. In both cases, MLP network with the following structure was used:

- Eight neurons in the input layer, representing the input variables for both ANN models,

- Two hidden layers with different numbers of neurons, and

- One neuron in the output layer representing the output variables separately for each of the ANN models.

These two networks differ only in the number of neurons in their hidden layers. The structure of the adopted networks is presented in Fig. 4.

The number of the neurons in the hidden layers and the transfer (activation) functions for the neurons were modified during network learning. The following functions, available in the MATLAB Neural Network Toolbox, were applied.

- Linear transfer function: purelin,

- Log-sigmoid transfer function: logsig,

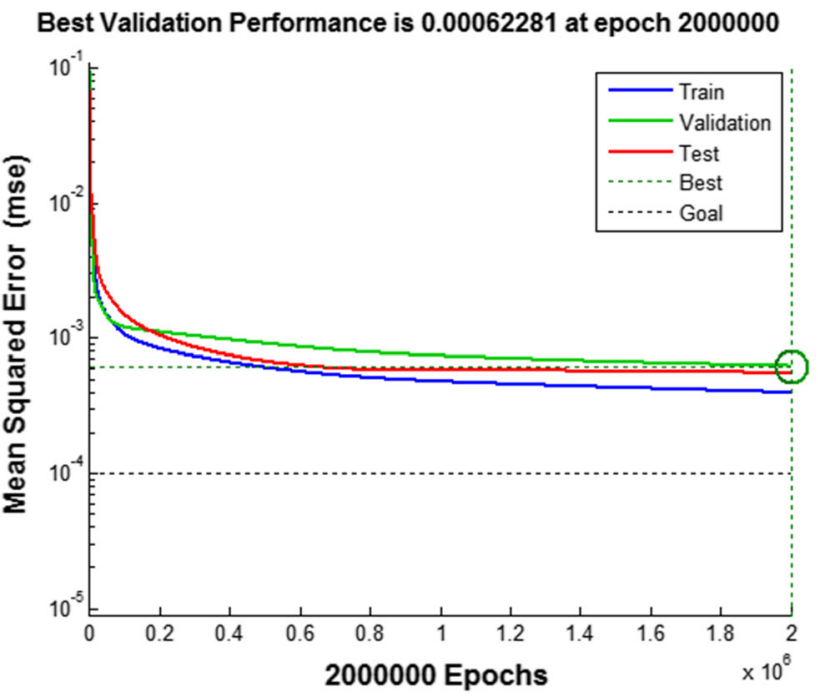

Fig. 5 Network training performance plot 
- Tan-sigmoid transfer function: tangsig.

Ultimately, the best results were obtained using the tangsig transfer function for neurons of both hidden layers.

Several network learning methods have been used. We started with the recommended first-choice supervised algorithm of a method called fastest backpropagation algorithm Levenberg-Marquardt (trainlm). Unfortunately, this method did not give us satisfactory learning results. Momentum learning methods were used in the next steps, namely gradient descent with momentum backpropagation (traingm), and gradient descent with momentum and adaptive learning rate backpropagation (traingdx). The best fit of models was obtained by applying the descent with momentum gradient method. Nevertheless, the calculation time using the four-core processor was quite long and lasted about $37 \mathrm{~h}$.

After many experiments, the traingdm training function, which updates weight and bias values according to gradient descent with momentum, was used for the network learning with parameters as follows:

(a)
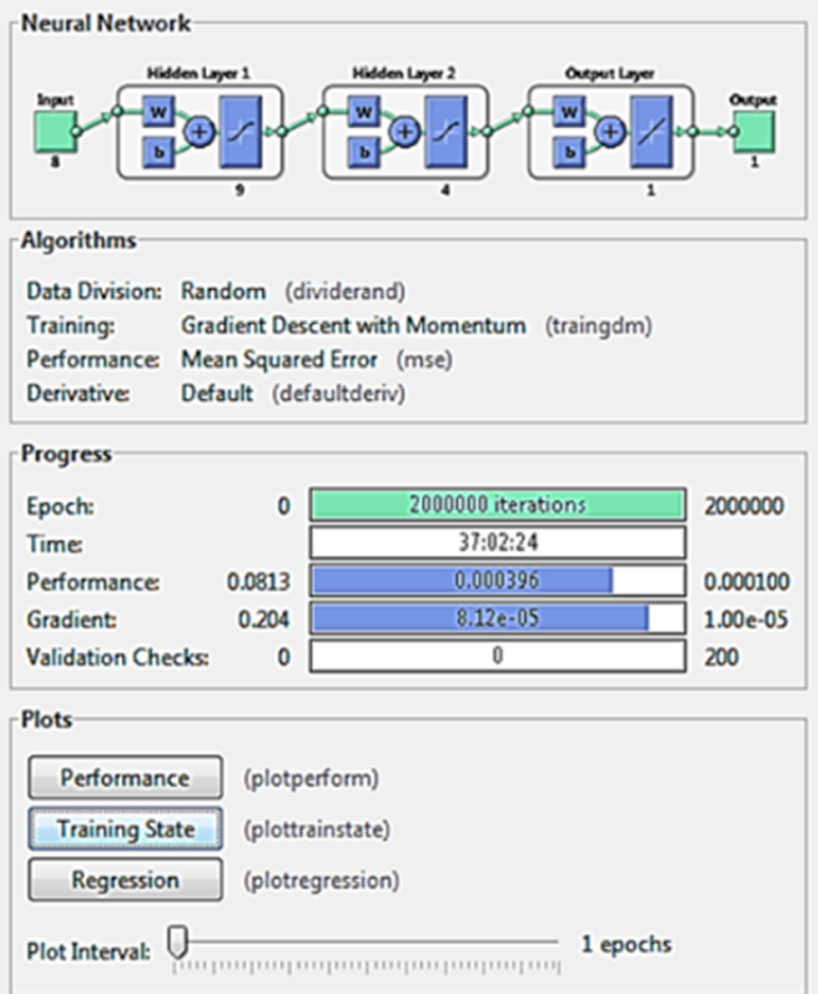

Opening Performance Plot

Stop Training
- mvnet.trainParam.show $=1$ (displaying results every 1 learning epoch),

- mvnet.trainParam.epochs $=2,000,000$ (the maximum number of learning epochs),

- mvnet.trainParam.goal $=0.0001$ (the value of mean squared error to be achieved during the learning process),

- mvnet.trainParam.max_fail $=200$ (the number of increasing learning errors checked on the validation set).

The maximum number of learning epochs was relatively easy to determine experimentally using the plot network performance function plotperform. While observing the graph of network learning, it was noticed that after reaching 2000000 epochs the network training essentially stops (Fig. 5).

The MATLAB diagrams of pattern recognition networks for both ANN models are shown in Fig. 6.

(b)
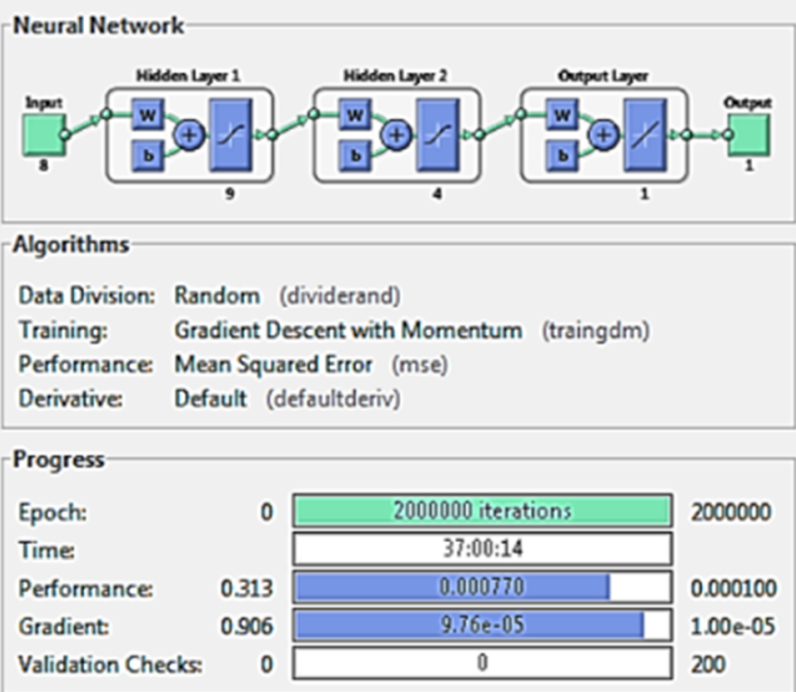

Plots

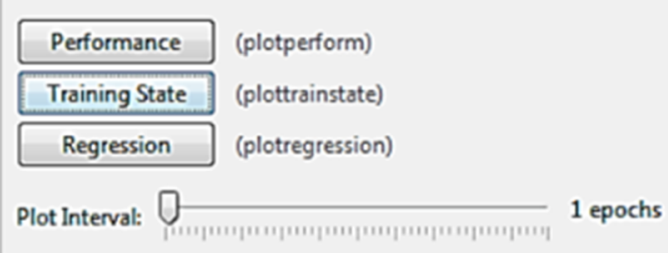

Opening Performance Plot Stop Training

Fig. 6 MATLAB diagrams of pattern recognition networks for ANN model outputs for: a hourly fuel consumption rate; $\mathbf{b}$ instantaneous speed over the ground 
(a)
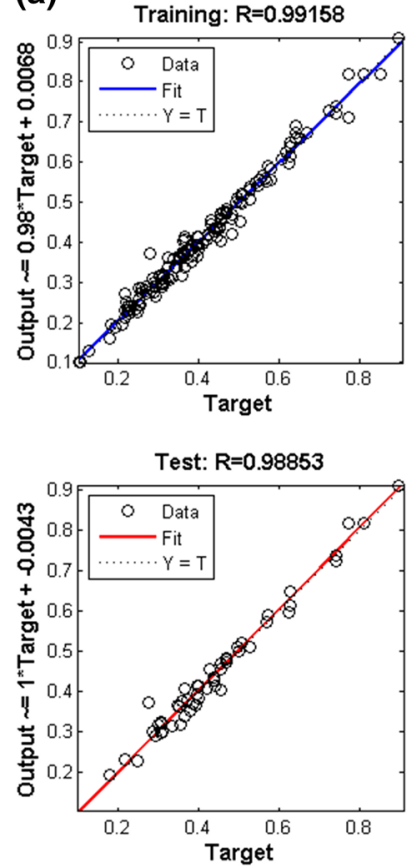
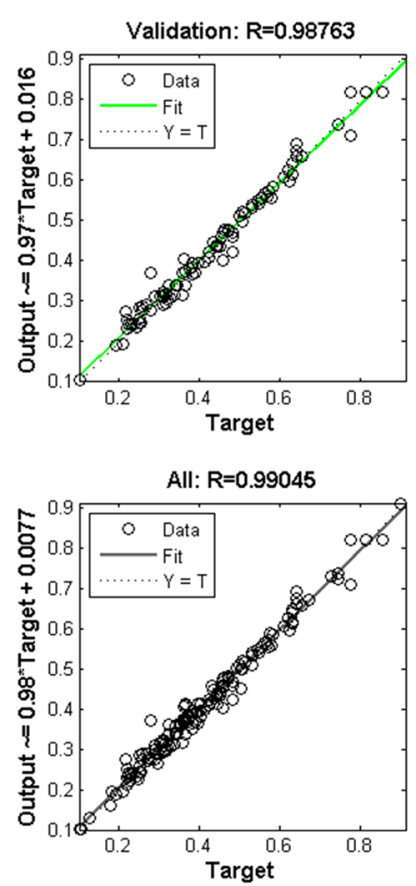

(b)
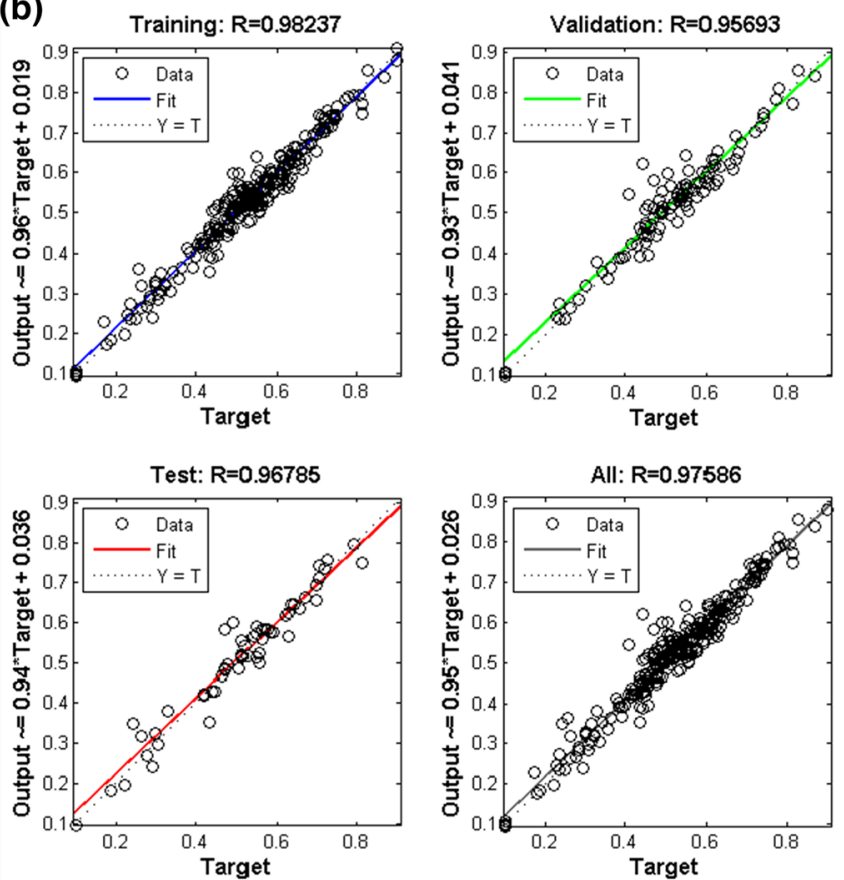

Fig. 7 MATLAB regression plots displaying the network outputs with respect to targets for training, validation, and test sets for: a hourly fuel consumption rate; $\mathbf{b}$ instantaneous speed over the ground

Table 2 Representative values of the input variables used to validate ANN models

\begin{tabular}{llllll}
\hline Variable identifier & \multicolumn{2}{l}{ Value of observation } & Unit \\
\cline { 2 - 5 } & No. 1 & No. 2 & No. 3 & No. 4 & \\
\hline$X_{1}$ & \multicolumn{2}{l}{ From 1000 to 1800 with steps of 200} & & [rpm] \\
$X_{2}$ & From 2 to 18 with steps of 2 & & & [Pitch scale] \\
$X_{3}$ & -80 & -50 & 50 & 90 & {$\left[{ }^{\circ}\right]$} \\
$X_{4}$ & 25 & 5 & 3 & 7 & {$[$ Knot] } \\
$X_{5}$ & 4 & 1 & 1 & 2 & {$[$ Degree] } \\
$X_{6}$ & -80 & -15 & 75 & 0 & {$\left[{ }^{\circ}\right.$ ] } \\
$X_{7}$ & 1 & 0.5 & 1 & 0 & {$[$ Knot] } \\
$X_{8}$ & 6 & 6 & 18 & 6 & {$[$ Months] } \\
\hline
\end{tabular}

\subsection{Quality assessment of ANN models}

The developed neural networks were fitted to the data by learning algorithms during a training process. The quality was proved using MATLAB regression plots that displayed the network outputs with respect to targets for training, validation and test sets (Fig. 7). In both cases, the quality of fits is reasonably good for all data sets, with $R^{2}$ values above 0.95 .

\section{Results and discussion}

To verify the correctness of the presented approach, additional sea trials were conducted after developing the computer-aided system. The representative values of the input variables (observations) are shown in Table 2. To avoid excessive concentration of lines on graphs representing relationships between the ANN model variables, these graphs were constructed for decision-making variable values with steps of $200[\mathrm{rpm}]$ for $X_{1}$ and 2 [pitch scale] for $X_{2}$. 


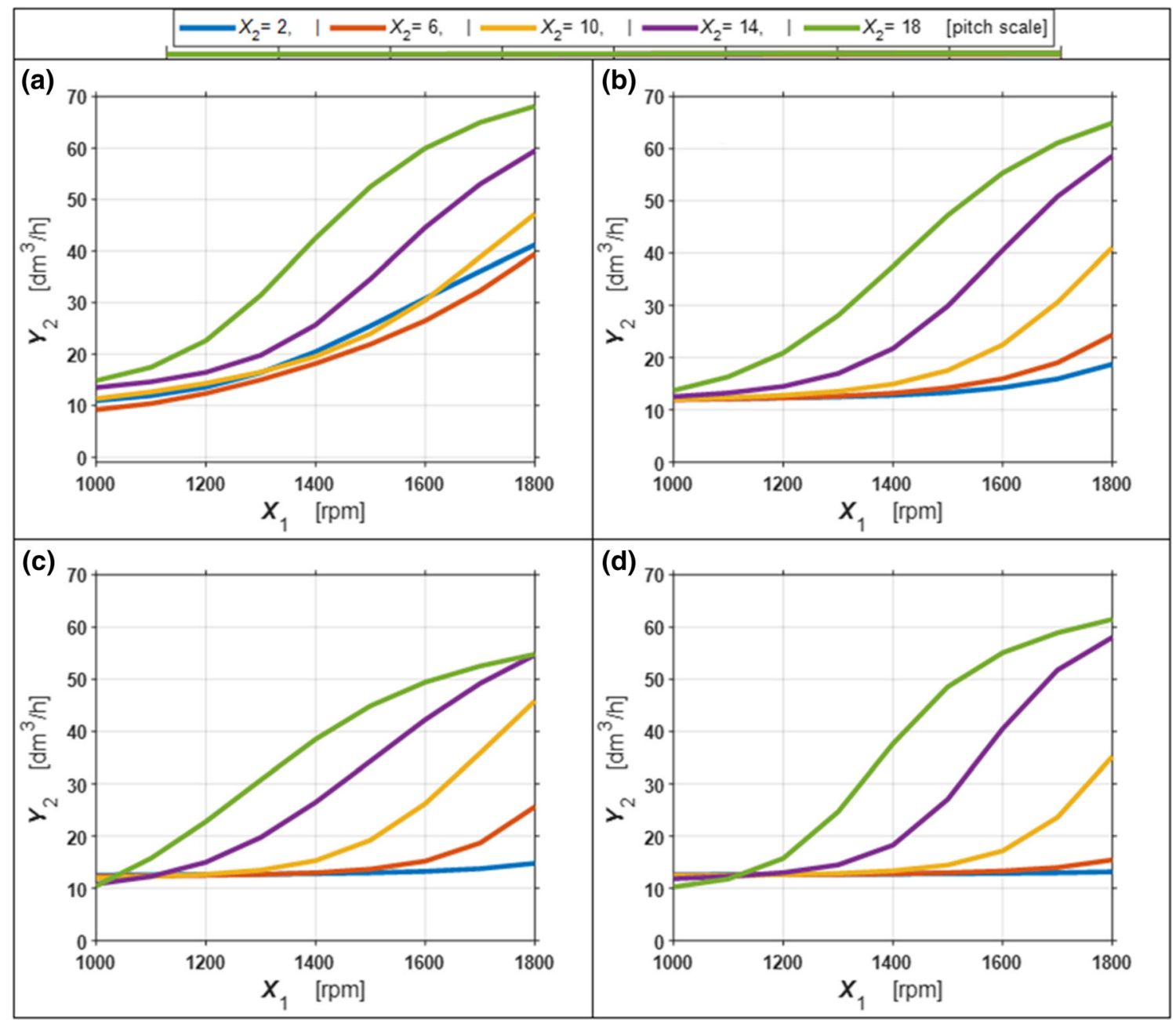

Fig. 8 Relationships between the output variable $Y_{1}$ 'hourly fuel consumption rate' and the decision-making variable $X_{1}$ 'rotational speed of the engine' for: a observation No.1; b observation No.2; c observation No.3; d observation No.4

The impact of the decision-making variables $X_{1}$ 'rotational speed of the engine' and $X_{2}$ 'pitch of the propeller' on the first output variable $Y_{1}$ 'hourly fuel consumption rate' for the representative values of the uncontrollable variables $X_{3}-X_{8}$ (Table 2) is shown in graphical form in Figs. 8 and 9, respectively. These same dependencies are collected together in a 3-D in Fig. 10.

An analysis of the constructed graphs shows us that the first developed ANN model that connects a fuel consumption process to factors that influence this process is a good representation of the ship operational practice. We notice very good smooth curves without any unexpected bends, bending or other undesirable distortions. However, we notice slight negative slopes of curves (Fig. 9c, d) for the minimum value of engine rotational speed $\left(X_{I}=100 \mathrm{rpm}\right)$ in cases when wind affects in the direction of the vessel's motion. This is consistent with observations during the operational practices of the tested ship, when the wind blowing from the stern drives provides additional thrust and simultaneously reduces the fuel consumption.

The received 2-D graphs (Figs. 8, 9) give us a basis to conclude that this representation

- Should be appropriate for the entire range of the decision-making variables $X_{1}$ and $X_{2}$, that is, for values ranging from 1000 to 1800 [rpm] and from 2 to 18 [pitch scale], respectively (Table 2). These values ranges are used in practice as the commanded outputs during operation of the tested ship,

- May be suitable for the uncontrollable variables $X_{3}-X_{8}$ in terms of their maximum values obtained during the sea trials (Table 1). 


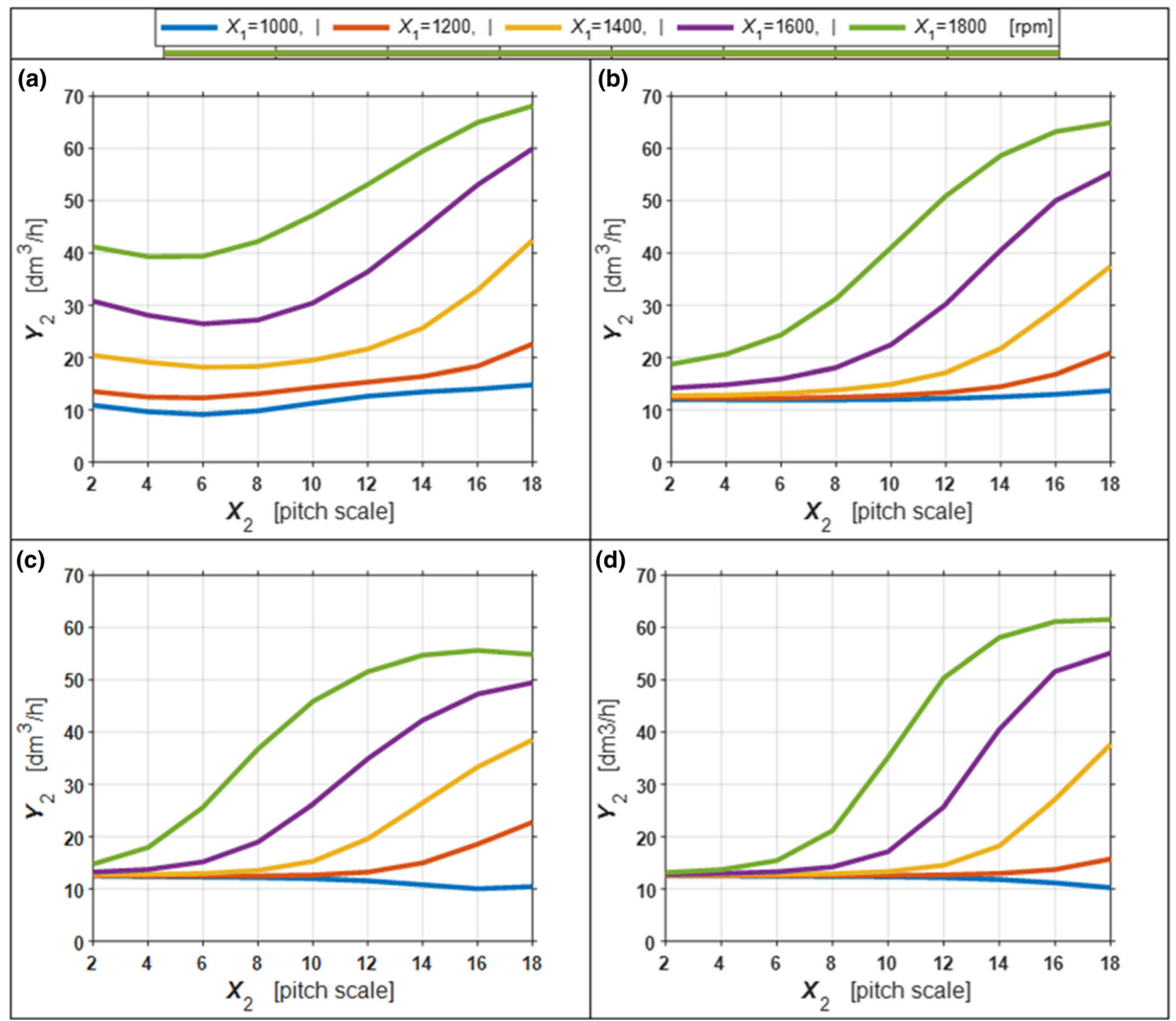

Fig. 9 Relationships between the output variable $Y_{1}$ 'hourly fuel consumption rate' and the decision-making variable $X_{1}$ 'rotational speed of the engine' for: a observation No.1; b observation No.2; c observation No.3; d observation No.4

These conclusions are also confirmed by the three-dimensional visualization presented in Fig. 10, where any unexpected bends, bending or other undesirable distortion, called 'sigmodal fluctuation' [24] do not appear.

Similar behaviour for the ANN model can be observed for the influence of the decision-making variables $X_{1}$ 'rotational speed of the engine' and $X_{2}$ 'pitch of the propeller' on the second output variable $Y_{2}$ 'instantaneous speed over the ground'. These dependencies are presented in graphical form in Figs. 11 and 12, respectively, for the representative values of the uncontrollable variables $X_{3}-X_{8}$ (Table 2).
Moreover, these same dependencies are collected together in the 3-D graphs presented in Fig. 13.

The second ANN model developed that links ship speed to factors that influence this speed is also a very good representation of the ship operational practice. Very good smooth curves without any unexpected bends, bending and negative slopes of curves characterize the presented graphs. Their courses also match the observations recorded during operation of the tested ship.

Based on the 2-D graphs (Figs. 11 and 12), we can conclude that this representation. 

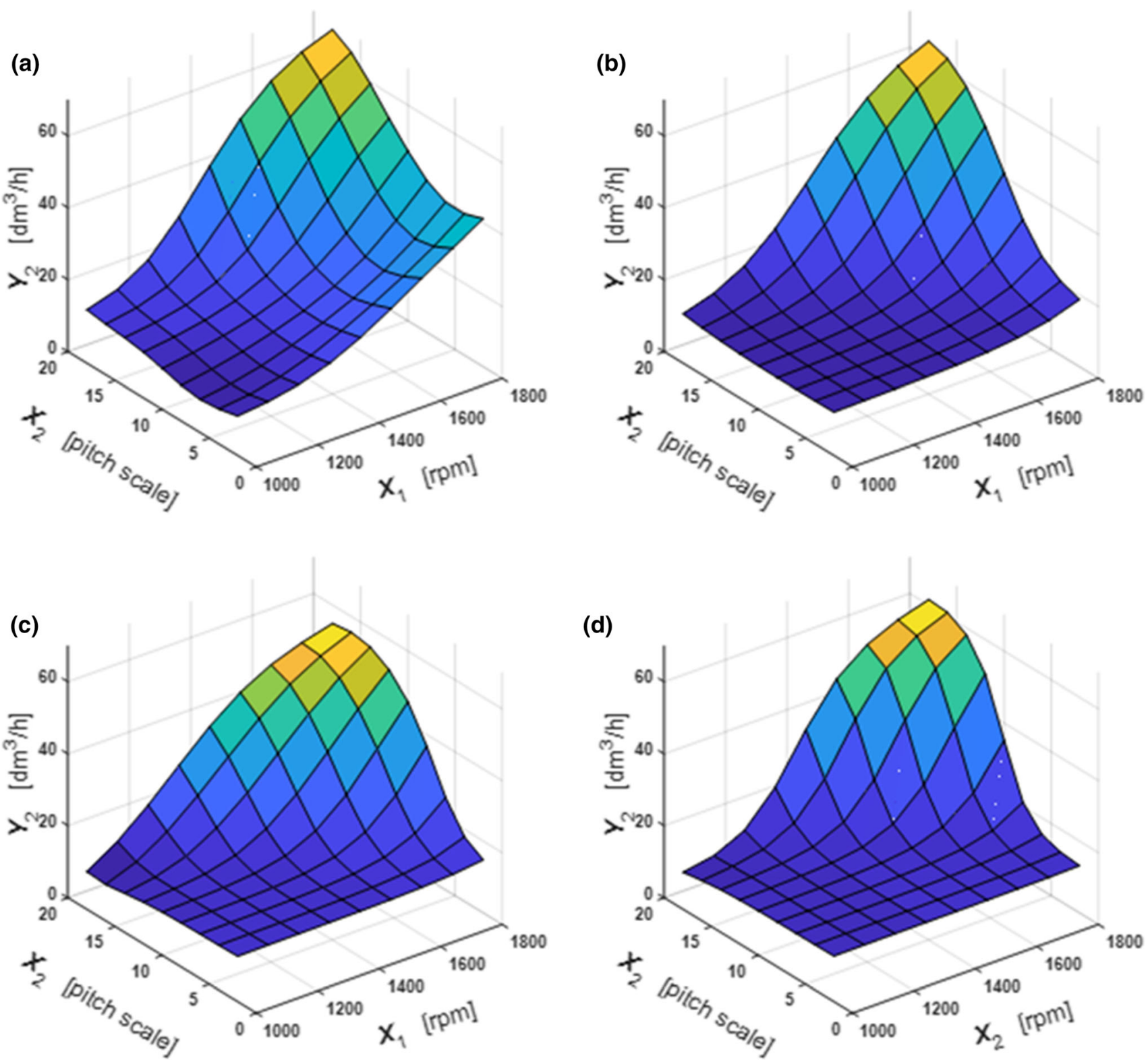

Fig. 10 Three-dimensional visualization of relationships between the output variable $Y_{1}$ 'hourly fuel consumption rate' and both the decision-making variables $X_{1}$ 'rotational speed of the engine' and $X_{2}$

- Should be appropriate for the entire range of decisionmaking variables $X_{1}$ and $X_{2}$, that is, for values from 1000 to 1800 [rpm] and from 2 to 18 [pitch scale], respectively (Table 2). These values are used in practice as the commanded outputs during operation of the tested ship,

- May be suitable for the uncontrollable variables $X_{3}-X_{8}$ in terms of their maximum values obtained during the sea trials (Table 1).

'pitch of the propeller' for: a observation No.1; b observation No.2; c observation No.3; d observation No.4

These conclusions are also confirmed by the three-dimensional visualization presented in Fig. 13, where any unexpected bends, bending or other undesirable distortion, called 'sigmodal fluctuation' [24], also do not appear.

Analysis of the modelling results for each of the ANN networks by observing parameters that characterize the quality of their fitting to the data recorded during sea trials as well as analysis of graph curve courses (Figs. 8, 9, 11 


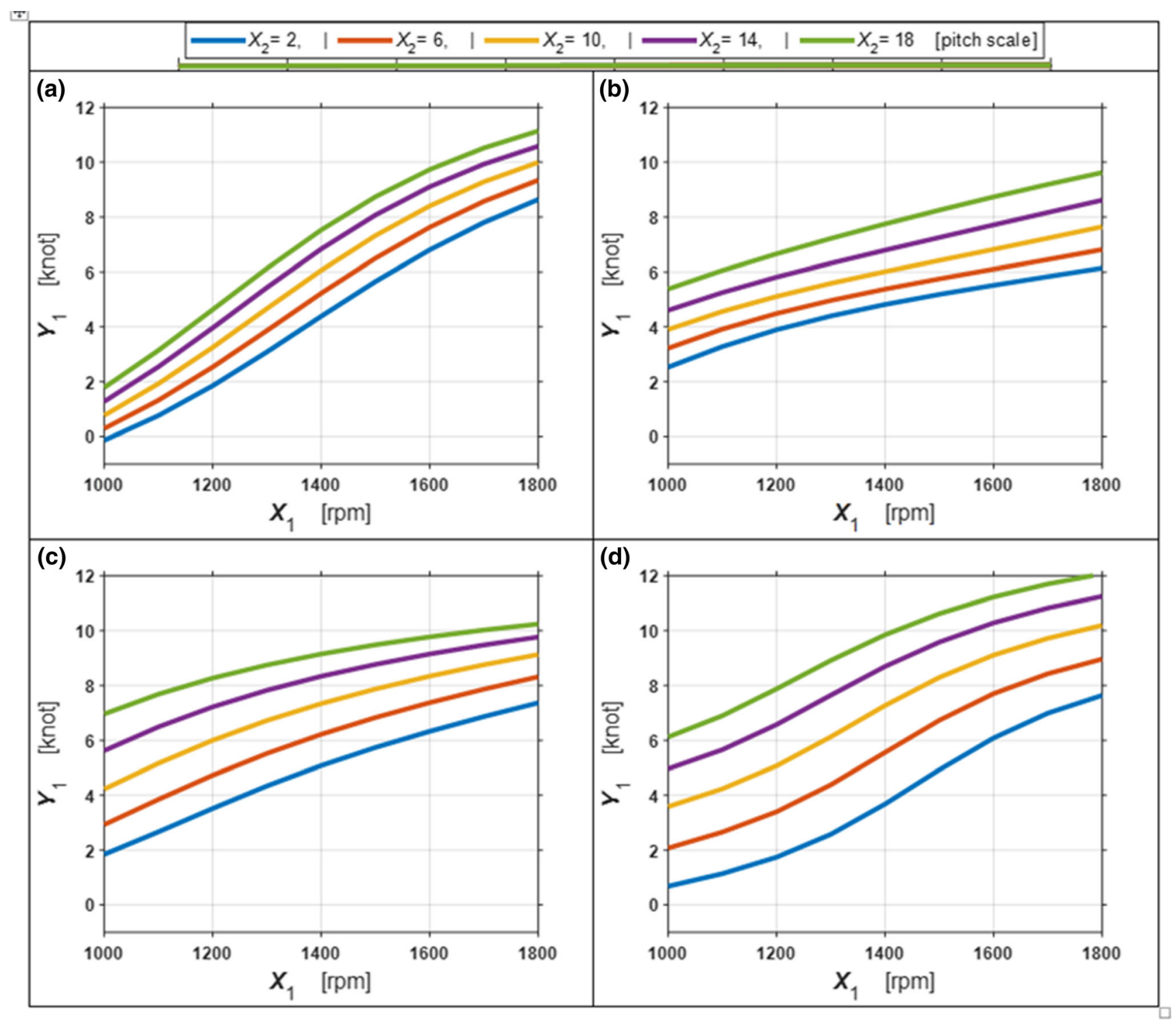

Fig. 11 Relationships between the output variable $Y_{2}$ 'instantaneous speed over the ground' and the decision-making variable $X_{1}$ 'rotational speed of the engine' for: a observation No.1; b observation No.2; $\mathbf{c}$ observation No.3; d observation No.4

and 12) for various values of the model input variables allows us to formulate the following statements:

- The developed neural networks are well fitted to the real data as evidenced by the relatively high correlation coefficient $\mathrm{R}^{2}$ and a lack of 'sigmodal fluctuation' in the MLP class models,

- There are some troubles with fitting the observed parameters in the areas where there was a lack of sea trail data or their observation number was low.

\section{Conclusions}

Prediction of ship driveline system performance was carried out for various ranges of the decision-making variables (commanded outputs) for numerous of uncontrollable variables (mainly sea environmental conditions) and disturbances (quantity of fuel in tanks, etc.).

The results obtained for modelling ship speed fuel and consumption by applying ANN allow concluding that:

- Application of ANN allows us to predict ship driveline system performance with $0.8-2.8 \%$ accuracy, which is 


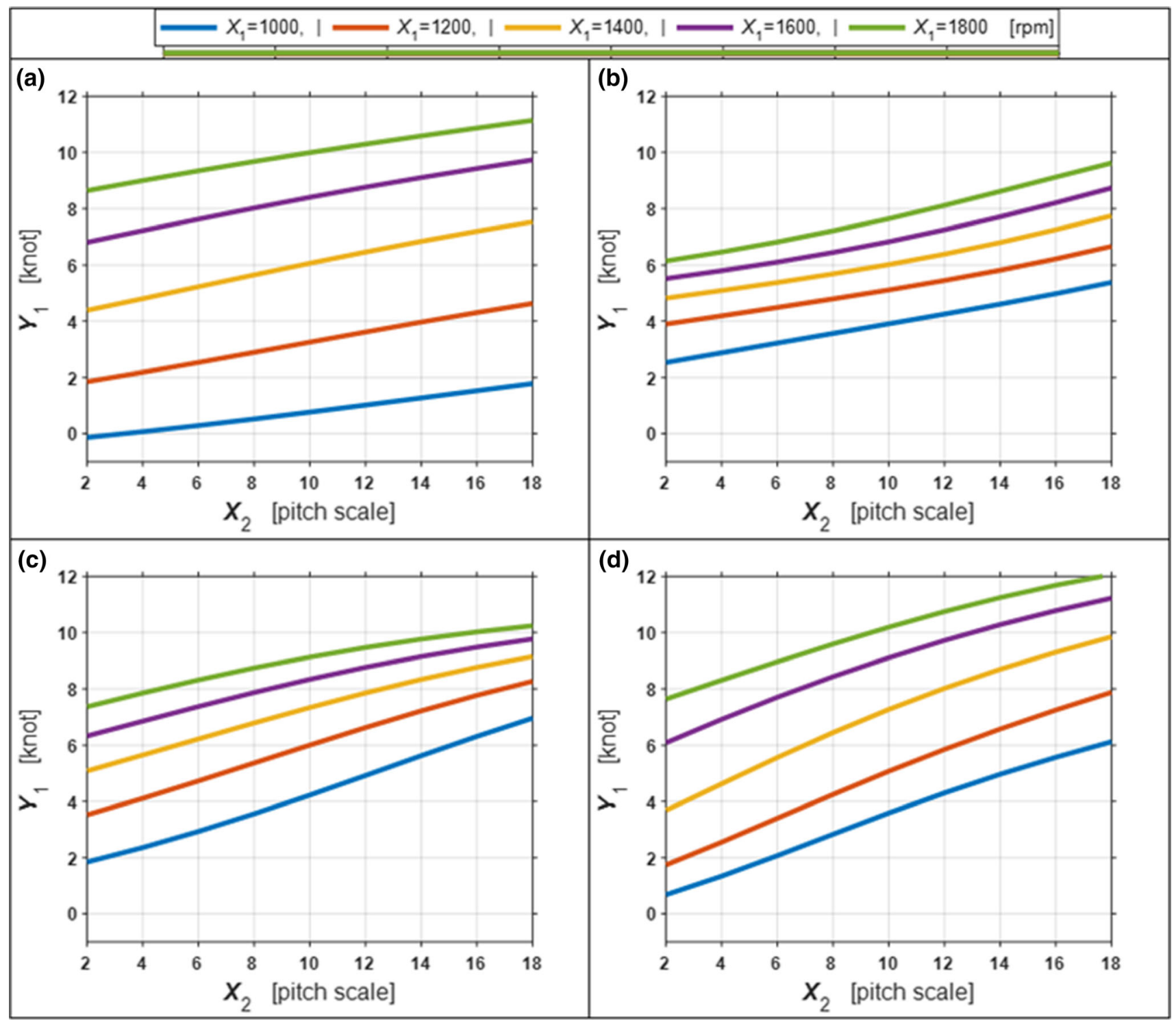

Fig. 12 Relationships between the output variable $Y_{2}$ 'instantaneous speed over the ground' and the decision-making variable $X_{1}$ 'rotational speed of the engine' for: a observation No.1; b observation No.2; c observation No.3; $\mathbf{d}$ observation No.4

as the same accuracy as results of measurement achieved during the ship sea trials,

- However, the recorded sea trial data are discrete values in their nature while the applied ANN of MLP class models provide continuous functions,

- The developed ANNs setting up black box models can be used to build the decision support system aiding selection of the commanded output of ship driveline system.
The developed two-objective optimization model provides different combinations of optimal commanded outputs, whereas expected values of the output variables (ship speed and fuel consumption) are similar. Therefore, future research should be conducted with additional optimization criteria, e.g. harmful air pollutants, including particulate matter $(\mathrm{PM})$, sulphur dioxide $\left(\mathrm{SO}_{2}\right)$, nitrogen oxides $\left(\mathrm{NO}_{\mathrm{x}}\right)$ emitted from ship engine. 

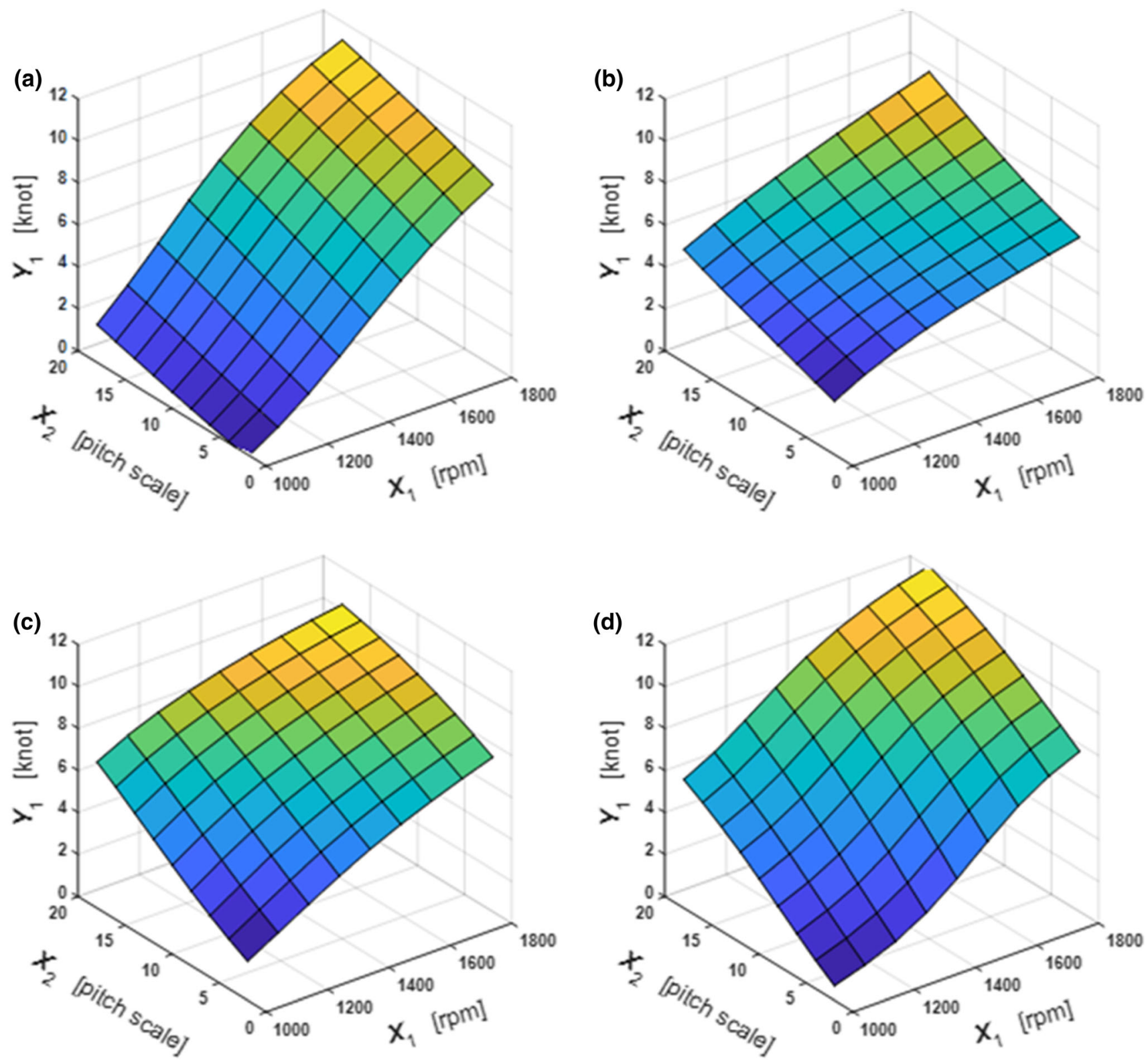

Fig. 13 Three-dimensional visualization of relationships between the output variable $Y_{2}$ 'instantaneous speed over the ground' and both the decision-making variables $X_{1}$ 'rotational speed of the engine' plus $X_{2}$

Open Access This article is licensed under a Creative Commons Attribution 4.0 International License, which permits use, sharing, adaptation, distribution and reproduction in any medium or format, as long as you give appropriate credit to the original author(s) and the source, provide a link to the Creative Commons licence, and indicate if changes were made. The images or other third party material in this article are included in the article's Creative Commons licence, unless indicated otherwise in a credit line to the material. If material is not included in the article's Creative Commons licence and your intended use is not permitted by statutory regulation or exceeds the permitted use, you will need to obtain permission directly from the copyright holder. To view a copy of this licence, visit http://creativecommons. org/licenses/by/4.0/.

'pitch of the propeller' for: a observation No. 1; b observation No. 2; c observation No. 3; d observation No. 4

\section{References}

1. Rudzki K (2014) Two-objective optimization of engine ship propulsion settings with controllable pitch propeller using artificial neural networks (in Polish). PhD thesis, Gdynia Maritime University

2. Asproulis N, Drikakis D (2013) An artificial neural networkbased multiscale method for hybrid atomistic-continuum simulations. Microfluidics Nanofluidics 15(4):559-574. https://doi. org/10.1007/s10404-013-1154-4

3. Asproulis N, Drikakis D (2009) Nanoscale materials modelling using neural networks. J Comput Theor Nanosci 6(3):514-518. https://doi.org/10.1166/jctn.2009.1062 
4. Rajchakit G, Pratap A, Raja R, Cao J, Alzabut J, Huang C (2019) Hybrid control scheme for projective lag synchronization of Riemann-Liouville sense fractional order memristive bam neural networks with mixed delays. Mathematics 7(8):759. https://doi. org/10.3390/math7080759

5. Rajchakit G, Chanthorn P, Kaewmesri P, Sriraman R, Lim CP (2020) Global Mittag-Leffler stability and stabilization analysis of fractional-order quaternion-valued memristive neural networks. Mathematics 8:422. https://doi.org/10.3390/math8030422

6. Niamsup P, Rajchakit M, Rajchakit G (2013) Guaranteed cost control for switched recurrent neural networks with interval timevarying delay. J Inequ Appl. https://doi.org/10.1186/1029-242x2013-292

7. Radonjic A, Pjevcevic D, Maras V (2020) Neural network ensemble approach to pushed convoys dispatching problems. Polish Maritime Res 27(1):70-82. https://doi.org/10.2478/pomr2020-0008

8. Pan L (2018) Exploration and mining learning robot of autonomous marine resources based on adaptive neural network controller. Polish Maritime Res. https://doi.org/10.2478/pomr-20180115

9. Qiang L, Bing-Dong Y, Bi-Guang H (2013) Calculation and measurement of tide height for the navigation of ship at high tide using artificial neural network. Polish Maritime Res. https://doi. org/10.2478/pomr-2018-0118

10. Hollenbach U (1999) Estimating resistance and propulsion for single-screw and twin screw ships. In: International conference on computer applications in shipbuilding. MIT vol 2 pp 237-250

11. Holtrop J, Mennen GG (1982) An approximate power prediction method. Int Shipbuild Prog 29:166

12. Rudzki K, Tarelko W (2016) A decision-making system supporting selection of commanded outputs for a ship's propulsion system with a controllable pitch propeller. Ocean Eng 126:254-264

13. Arslan O, Bal Beşikçi E, Ölçer AI (2015) Improving energy efficiency of ships through optimisation of ship operations. IAMU 2014 Research Project (No. 20140301). Istanbul Technical University: p 77. http://iamu-edu.org/wp-content/uploads/ 2015/06/Final-report-RP2014-20140301-ITUMF.pdf
14. Bal Beşikçi E, Arslan O, Turan O, Ölçer AI (2016) An artificial neural network based decision support system for energy efficient ship operations. Comput Oper Res 66:393-401. https://doi.org/ 10.1016/j.cor.2015.04.004

15. Pedersen BP, Larsen J (2009) Modeling of ship propulsion performance. In: World maritime technology conference pp 537-550

16. Yuquan D, Meng Q (2016) Models for ship fuel efficiency with applications to in-service ship fuel consumption management. Dissertation, National University of Singapore

17. Du Y, Meng Q, Wang Y (2016) Artificial neural network models for ship fuel efficiency with applications to in-service ship fuel consumption management. In: International conference on logistics and maritime systems. https://www.maritimestudies.nus. edu.sg/wp-content/uploads/2016/11/CMS-Research-UpdateNovember-2016-201601028.pdf Accessed 26 May 2019

18. Couser P, Mason A, Mason G, Smith CR, von Konsky BR (2004) Artificial neural networks for hull resistance prediction. In: Conference Compit pp 391-402

19. Grabowska K, Szczuko P (2015) Ship resistance prediction with artificial neural networks. In 2015 Signal Processing: Algorithms, Architectures, Arrangements, and Applications (SPA) 2015 https://doi.org/10.1109/spa.2015.7365154

20. Bishop CM (1995) Neural networks for pattern recognition. Oxford University Press, Oxford

21. Mason A, Couser P, Mason G, Smith CR, von Konsky BR (2005) Optimisation of vessel resistance using genetic algorithms and artificial neural networks. https://pdfs.semanticscholar.org/723b/ 24e942da01a2edd3fbe5cef4cbe5a1ec1b0d.pdf. Accessed 26 May 2019

22. Ortigosa I, López R, García J (2007) A neural networks approach to residuary resistance of sailing yachts prediction. In: International conference on marine engineering MARINE p 250

23. Ortigosa I, López R, García J (2009) Prediction of total resistance coefficients using neural networks. J Marit Res 6(3):15-26

24. Tadeusiewicz R (2007) Artificial neural networks (in Polish). Kurs StatSoft Polska, Krakow

Publisher's Note Springer Nature remains neutral with regard to jurisdictional claims in published maps and institutional affiliations. 